\title{
KIBRA and CLSTN2 polymorphisms exert interactive effects on human episodic memory
}

\author{
Claudia Preuschhof a,b,*, Hauke R. Heekeren ${ }^{\mathrm{a}, \mathrm{b}}$, Shu-Chen $\mathrm{Li}^{\mathrm{a}}$, Thomas Sander ${ }^{\mathrm{c}}$, \\ Ulman Lindenberger ${ }^{\mathrm{a}}$, Lars Bäckman ${ }^{\mathrm{d}}$ \\ a Max Planck Institute for Human Development, D-14197 Berlin, Germany \\ ${ }^{\mathrm{b}}$ Department of Psychology, Freie Universität Berlin, D-14195 Berlin, Germany \\ c Cologne Center for Genomics, D-50674 Cologne, Germany \\ d Aging Research Center, Karolinska Institute, S-17177 Stockholm, Sweden
}

\section{A R T I C L E I N F O}

\section{Article history:}

Received 24 July 2009

Received in revised form

23 September 2009

Accepted 28 September 2009

Available online 2 October 2009

\section{Keywords:}

Episodic memory

Associative demands

Genes and behavior

Gene-gene interactions

Hippocampus

Medial temporal lobe

\begin{abstract}
A B S T R A C T
Individual differences in episodic memory are highly heritable. Several studies have linked a polymorphism in the gene encoding the KIBRA protein to episodic memory performance. Results regarding CLSTN2, the gene encoding the synaptic protein calsyntenin 2, have been less consistent, possibly pointing to interactions with other genes. Given that both KIBRA and CLSTN2 are expressed in the medial temporal lobe and have been linked to synaptic plasticity, we investigated whether KIBRA and CLSTN2 interactively modulate episodic memory performance $(n=383)$. We replicated the beneficial effect of the KIBRA T-allele on episodic memory, and discovered that this effect increases with the associative demands of the memory task. Importantly, the memory-enhancing effect of the KIBRA T-allele was boosted by the presence of the CLSTN2 C-allele, which positively affected memory performance in some previous studies. In contrast, the presence of CLSTN2 C-allele led to reduced performance in subjects homozygous for the KIBRA C-allele. Overall, these findings suggest that KIBRA and CLSTN2 interactively modulate episodic memory performance, and underscore the need for delineating the interactive effects of multiple genes on brain and behavior.
\end{abstract}

(C) 2009 Elsevier Ltd. All rights reserved.

\section{Introduction}

Episodic memory enables humans to consciously remember past experiences that have occurred at a certain time in a certain place (Tulving, 1972, 2002). The formation of memory episodes requires the integration of multiple content and contextual features and depends on a cascade of molecular events (Squire \& Kandel, 1999). Evidence indicates that around $50 \%$ of the between-person variation in episodic memory performance is heritable (Alarcon, Plomin, Fulker, Corley, \& DeFries, 1998; Bouchard, Jr. \& McGue, 2003; Finkel, Pedersen, Plomin, \& McClearn, 1998; McClearn et al., 1997; Thapar, Petrill, \& Thompson, 1994). However, the genetic basis of individual differences in episodic memory remains unclear.

Animal studies have identified genes and signaling molecules important to memory (Dudai, 2002; Kandel, 2001; Shobe, 2002; Tonegawa, Nakazawa, \& Wilson, 2003; Waddell \& Quinn, 2001). More recently, it has been discovered that genetic variation in

* Corresponding author at: Department of Psychology, Freie Universität Berlin, Habelschwerdter Allee 45, D-14195 Berlin, Germany. Tel.: +49 30838 55724; fax: +493083852887 .

E-mail address: preuschhof@mpib-berlin.mpg.de (C. Preuschhof). the human homologues of memory-related signaling molecules contributes to interindividual differences in memory performance (for review see Koppel \& Goldberg, 2009). KIBRA (kidney and brain expressed protein; gene locus 5q34-q35.2), a scaffolding protein, is expressed in the murine and human brain, with the highest expression levels in the hippocampus and the temporal lobe (Johannsen, Duning, Pavenstadt, Kremerskothen, \& Boeckers, 2008; Papassotiropoulos et al., 2006), regions known to be involved in episodic memory (Davachi, 2006; Eichenbaum, Yonelinas, \& Ranganath, 2007; Rempel-Clower, Zola, Squire, \& Amaral, 1996; Scoville \& Milner, 1957; Squire, Wixted, \& Clark, 2007; ZolaMorgan, Squire, \& Amaral, 1986). KIBRA has been proposed to be involved in processes important to episodic memory formation, such as signal transduction, synaptic plasticity, long-term potentiation, and synaptic transmission (Buther, Plaas, Barnekow, \& Kremerskothen, 2004; Johannsen et al., 2008; Kremerskothen et al., 2003). In the rat brain, KIBRA expression is highest during the early stages of synaptogenesis and might therefore play an important function in brain development besides its role in modifying existing synapses (Johannsen et al., 2008).

A genome-wide association study by Papassotiropoulos et al. (2006) showed that a single nucleotide polymorphism (SNP) in the KIBRA gene, leading to a common $\mathrm{C} \rightarrow \mathrm{T}$ substitution within 
intron 9 (rs17070145), is associated with individual differences in episodic memory. Carriers of the rs17070145 T-allele exhibited a clear advantage in delayed episodic recall compared to individuals lacking the T-allele. This effect was confirmed in two independent cohorts of young Swiss and young to very old US subjects.

Four subsequent studies have replicated these findings in samples of elderly persons (Almeida et al., 2008; Bates et al., 2009; Corneveaux et al., in press; Schaper, Kolsch, Popp, Wagner, \& Jessen, 2008). However, another study failed to confirm an association between the KIBRA polymorphism and episodic memory in two independent samples (Need et al., 2008), and a study in adolescents also genotyped the KIBRA polymorphism but did not report any significant association between KIBRA status and episodic memory (Jacobsen, Picciotto, Heath, Mencl, \& Gelernter, 2009). Further, an opposite effect of higher episodic memory performance in non-T carriers was found in a sample of elderly participants with subjective memory complaints (Nacmias et al., 2008). The risk for late-onset Alzheimer's disease, which is associated with a severe episodic memory impairment, has also been linked to genetic variations in KIBRA, with one study reporting an increased risk for T-allele carriers (Rodriguez-Rodriguez et al., 2009) and another finding an increased risk for non-carriers of the T-allele (Corneveaux et al., in press).

A possible reason for these inconsistent results is that complex cognitive functions such as episodic memory are influenced by multiple genes (Lindenberger et al., 2008; McClearn, 2006; Nagel et al., 2008; Stelzel, Basten, Montag, Reuter, \& Fiebach, 2009; Tan et al., 2007; Yacubian et al., 2007). Therefore, the effect of a single gene likely depends on the background effects of other interacting genetic modifiers. Interestingly, in the study by Papassotiropoulos et al. (2006), an additional association between episodic memory and a SNP of the CLSTN2 gene (gene locus: 3q23), a common $\mathrm{T} \rightarrow \mathrm{C}$ substitution (dbSNP: rs6439886), was found: Carriers of the CLSTN2 rs6439886 C-allele showed higher performance than noncarriers. Although this effect was not confirmed in another sample in the same study, a recent study in adolescents also reported that carriers of the CLSTN2 C-allele outperformed non-carriers in episodic memory (Jacobsen et al., 2009). The CLSTN2 gene encodes the synaptic protein calsyntenin 2 , one of the three calsyntenin family members found in humans (Hintsch et al., 2002). Calsyntenins are predominantly expressed in the central nervous system including the medial temporal lobe (MTL); they are components of the postsynaptic membrane of predominantly asymmetric excitatory synapses and are found with the highest levels in GABAergic neurons (Hintsch et al., 2002). Calsyntenins seem to play a role in postsynaptic signaling (Hintsch et al., 2002). Casy-1 found in C. elegans is a homologue of human CLSTN2 (Hoerndli, Walser, \& Frohli, 2009). Importantly, casy-1 mutants show deficits in associative learning paradigms and expression of human CLSTN2 reverses the behavioral deficits of casy-1 mutants (Hoerndli et al., 2009; Ikeda et al., 2008).

Collectively, the above studies indicate that individual differences in both the KIBRA and the CLSTN2 genotypes can modulate episodic memory performance. However, it remains unknown whether these two SNPs have an interactive effect on episodic memory. It is possible that certain genotypic combinations of KIBRA and CLSTN2 cancel out their effects on episodic memory, whereas others may potentiate effects leading to inconsistent results, depending on genotypic distribution in different study samples.

The MTL, and the hippocampus in particular, which is critically implicated in episodic memory (Davachi, 2006; Eichenbaum et al., 2007; Rempel-Clower, Zola, Squire, \& Amaral, 1996; Scoville \& Milner, 1957; Squire et al., 2007; Zola-Morgan et al., 1986), might be possible target regions for an interactive effect of KIBRA and CLSTN2, because both genes are expressed at high levels in these brain regions and both genes have been associated with synaptic plasticity (Hintsch et al., 2002; Kremerskothen et al., 2003; Papassotiropoulos et al., 2006). In addition, neuroimaging studies show that both the KIBRA (Papassotiropoulos et al., 2006) and the CLSTN2 (Jacobsen et al., 2009) genotypes influence hippocampal activity during episodic memory retrieval.

The associative binding of different pieces of content and contextual information into complex memory episodes is an important aspect of episodic memory (Naveh-Benjamin, 2000; Tulving, 1972, 2002). The hippocampus is crucial for these binding operations and the level of hippocampal activation reflects the associative demands of the memory task and retrieval success (Achim, Bertrand, Montoya, Malla, \& Lepage, 2007; Addis \& McAndrews, 2006; Davachi, Mitchell, \& Wagner, 2003; Davachi \& Wagner, 2002; Giovanello, Schnyer, \& Verfaellie, 2004; Henke, Weber, Kneifel, Wieser, \& Buck, 1999; Mitchell, Johnson, Raye, \& D’Esposito, 2000; Ranganath, Cohen, Dam, \& D’Esposito, 2004; Staresina \& Davachi, 2008; Yonelinas, Hopfinger, Buonocore, Kroll, \& Baynes, 2001). Thus, the effects of the KIBRA and CLSTN2 polymorphisms on episodic memory may be modulated by the associative demands of the task.

We investigated whether interindividual variations in the KIBRA and CLSTN2 genes modulate episodic memory performance. Specifically, we asked the following questions: First, do the KIBRA and the CLSTN2 polymorphisms interactively affect episodic memory performance? Second, are these genetic influences modulated by the associative demands of the memory task? Based on previous studies, we predicted that carriers of the KIBRA T-allele who also carry the CLSTN2 C-allele would show higher episodic memory performance than carriers of the other allelic combinations. Both genes are expressed in high levels in the hippocampus, a brain region critical to associative binding of items in episodic memory, and the KIBRA and the CLSTN2 genotypes modulate hippocampal activity during episodic retrieval. Hence, we also predicted that a potential interactive effect between the two genes should be affected by the associative demands of the task.

\section{Material and methods}

\subsection{Participants}

A total of 383 healthy volunteers participated in the study (214 men/169 women; mean age $=25.7$ years, SD: 2.93 , age range $=20-31$ ). All participants were of Caucasian origin, right-handed, had normal or corrected vision, and reported no history of neurological or psychiatric disorder including drug addition. Also, the sample did not include individuals who were smoking more than 10 cigarettes per day. Participants were recruited via newspaper advertisements, advertisements in public transportation trains, or flyers in bars and restaurants. All participants were paid for participation and gave written informed consent prior to the study. The study was approved by the Ethics Committee of the Charite University Medicine, Berlin. Participants were categorized according to their allelic variants of the KIBRA and CLSTN2 polymorphisms. For a detailed sample description, see Table 1.

\subsection{Genotyping}

DNA was extracted from peripheral blood samples using standard methods. Genotyping of the KIBRA SNP rs17070145 and the CLSTN2 SNP rs6439886 was carried out in a 384-well microtiter plate format using TaqMan $5^{\prime}$-exonuclease assay. Both SNPs were selected from the dbSNP (http://www.ncbi.nlm.nih.gov/SNP/). The sequences of primers and TaqMan probes for the SNP genotyping were designed and synthesized by Applied Biosystems (Foster City, CA, USA).

The frequencies of the KIBRA rs 17070145 genotypes were $44.2 \%$ for C/C, $41.3 \%$ for $\mathrm{C} / \mathrm{T}$, and $14.5 \%$ for $\mathrm{T} / \mathrm{T}$. The frequencies for the three CLSTN2 genotypes were $2.1 \%$ for $\mathrm{C} / \mathrm{C}, 21.6 \%$ for $\mathrm{C} / \mathrm{T}$ and $76.3 \%$ for TT. The observed genotypic distribution of both SNPs did not deviate significantly from that expected according to Hardy-Weinberg equilibrium $(p>0.05)$.

Following Papassotiropoulos et al. (2006), we combined the two genotype groups carrying the T-allele of the KIBRA SNP rs17070145 and the two genotype groups carrying the C-allele of the CLSTN2 SNP rs6439886 (Table 1). 
Table 1

Demographic and cognitive variables.

\begin{tabular}{|c|c|c|c|c|}
\hline \multirow{2}{*}{$\begin{array}{l}\text { Genotype KIBRA } \\
\text { CLSTN2 }\end{array}$} & \multicolumn{2}{|l|}{$\mathrm{C} / \mathrm{C}$} & \multicolumn{2}{|l|}{ T-carrier } \\
\hline & $\mathrm{T} / \mathrm{T}$ & C-carrier & $\mathrm{T} / \mathrm{T}$ & C-carrier \\
\hline \multicolumn{5}{|l|}{ Demographics } \\
\hline$n$ & $129(34 \%)$ & $40(10 \%)$ & $163(43 \%)$ & $51(13 \%)$ \\
\hline Men/women & $83 / 46$ & $26 / 14$ & $77 / 86$ & $28 / 23^{a}$ \\
\hline Age (SD) & $25.7(2.9)$ & $25.2(3.0)$ & $25.8(2.9)$ & $25.7(3.1)^{b}$ \\
\hline Years of education (SD) & $12.6(1.3)$ & $12.4(1.3)$ & $13.3(6.9)$ & $12.6(1.0)^{b}$ \\
\hline Non-smoker/smoker & $93 / 36$ & $26 / 14$ & $122 / 41$ & $36 / 15^{c}$ \\
\hline \multicolumn{5}{|l|}{ Cognitive measures } \\
\hline WCST $^{d}$ & $12.0(6.9)$ & $12.4(4.6)$ & $11.9(5.4)$ & $11.2(5.0)^{b}$ \\
\hline WCST $^{e}$ & $69.0(9.6)$ & $68.7(10.8)$ & $69.1(8.7)$ & $69.4(8.2)^{b}$ \\
\hline SWM task: load $4^{\mathrm{f}}$ & $0.93(0.07)$ & $0.94(0.06)$ & $0.94(0.06)$ & $0.96(0.04)^{\mathrm{b}}$ \\
\hline SWM task: load $7^{\mathrm{f}}$ & $0.81(0.08)$ & $0.81(0.07)$ & $0.81(0.07)$ & $0.82(0.06)^{b}$ \\
\hline Digit symbol test $(S D)^{g}$ & $61.9(12.0)$ & $59.90(10.4)$ & $61.3(11.7)$ & $61.0(11.3)^{b}$ \\
\hline Spot-a-word test $(\mathrm{SD})^{\mathrm{h}}$ & $17.9(5.5)$ & $16.5(5.2)$ & $18.3(5.4)$ & $17.3(5.8)^{b}$ \\
\hline
\end{tabular}

a $\chi^{2}(3)=10.05, p=.018$.

b Three-way analyses of variance $=$ n.s.

c $\chi^{2}$-test $=$ n.s.

d Number of perseverative errors.

e Sum of correct responses.

f Relative accuracy.

g Total number of completed items.

h Number of correct responses.

\subsection{Experimental tasks}

Participants underwent two sessions of psychometric and cognitive testing, lasting approximately $2.5 \mathrm{~h}$ each, with a 7-day interval between the sessions. Testing was done in groups of five to six persons, with each participant remaining in the same group for both sessions. Other than episodic memory, the cognitive battery included tests assessing executive functioning (Wisconsin Card Sorting Test (WCST), spatial working memory (SWM), as well as fluid (Digit Symbol) and crystallized (Spot-a-Word) intelligence. To assess whether the effects of the KIBRA and CLSTN2 polymorphisms are particularly pronounced in episodic memory, we also examine genetic effects pertaining to the remaining cognitive domains. Participants also filled out demographic questionnaires.

\subsubsection{Item-pair memory task}

The episodic memory task involved four conditions that were presented sequentially in one session. During an initial study phase, subjects were visually presented with pairs of unrelated words, und were instructed to study each pair under two conditions, as either two single words (item instruction) or as a pair of words (pair instruction). Thus, in the item instruction condition, word pairs were learned incidentally, whereas the pair-instruction condition emphasized the intentional association between words. Therefore, both conditions differ in their strategic and associative requirements. Words were German nouns varying from 4 to 9 letters and 1-4 syllables. The study phase of each condition contained 30 pairs of semantically unrelated words. Each word pair was presented for $6 \mathrm{~s}$. After the study phase, subjects were presented with a number (e.g. 335). They were then required to count backwards in steps of three (i.e., 335-332-329) for $90 \mathrm{~s}$ to prevent rehearsal and minimize the influence of short-term memory. Then, the test phase started. In one condition (item recognition), subjects were asked to decide whether or not they had seen the presented word during the study phase. Half of the presented words were old, and the other half was new. In a second condition (associative recognition), subjects had to decide whether a presented word pair had been presented during the study phase or not. Half of the presented words were old, and the other half was formed by recombining words in the previously studied list of word pairs. In the recognition phase, 30 words or word pairs were presented for $4 \mathrm{~s}$ each. Decisions were made by pressing one of two different response buttons. The two factors, study instruction and recognition test, were combined in a $2 \times 2$ factorial design resulting in four different conditions. These conditions were presented in the following order: (1) item instruction - item test, (2) item instruction - associative test, (3) pair instruction - associative test, (4) pair instruction - item test. Before these 4 experimental conditions, subjects practiced the task with the item instruction - item test condition. Each word or word pair was presented on the same vertical level at the center of a computer screen with five horizontal spaces between the words in a pair. Words were written in white letters on black background (viewing distance about $60 \mathrm{~cm})$.

2.3.2. Measures of executive functioning and working memory

2.3.2.1. Wisconsin card sorting test. A computer-administered adapted version of the standard 128-cards WCST was used (Heaton, Chelune, Talley, Kay, \& Curtis, 1993). This task is considered as a standard neuropsychological index of executive functioning. Four key cards are presented at the top of the screen. A response card

is shown at the bottom center of the screen and has to be sorted by the participant to one of the deck of cards presented on the top of the screen. The cards can be matched based on three dimensions: color, form, and number. Subjects respond by pressing one of the four corresponding buttons with the index finger of the right hand. A limited time is given to allow participants to correct their answer Then, feedback about the correctness of the response appears briefly on the screen. Participants must use this feedback to sort the next response card as no explicit information about the current sorting rule or the switch to a new sorting rule is provided. The first sorting principle is color, followed by form and then number. When a person attains 10 correct consecutive sorting orders (referred to as completing a category), the sorting principle changes (in the order noted). This sequence is repeated once. Because no warning is given about these changes, the subjects must make the necessary shift of mental set on the basis of the feedback given. The test continues until six categories have been completed or until the entire set of 128 cards has been sorted. Performance was evaluated by applying the WCST standard administration procedure and scoring rules as described by (Heaton et al., 1993). The percentage of perseverative errors and sum of correct responses were used to index performance.

2.3.2.2. Spatial working memory task. We modified a computerized SWM task devised by (Klingberg, O'Sullivan, \& Roland, 1997). In this task, participants were visually presented with a series of dots, displayed consecutively in a specific location on a $4 \times 4$ grid of circles. They had to decide if a dot was presented on the position of a specific circle (i.e. location memory condition). If subjects responded "yes" to the spatial location, a digit was presented in this position. Subjects then had to decide if the digit matched the serial position of the dot in the presented order (i.e. sequence memory condition). They responded with a right index-button press if the location or the serial position was correct, and with a left index-button press if the location or serial position was wrong. Load level was manipulated by the number of dots in the sequence; either four or seven (i.e., set size 4 and set size 7 conditions, respectively). One third of the items were associated with correct location and temporal order, one third with correct location and incorrect order, and another third with incorrect location (and, by implication, missing order information). The timing of the sequence was set up with a $1000 \mathrm{~ms}$ fixation, immediately followed by the stimulus presentation ( $600 \mathrm{~ms}$ per dot) and a marked circle for a maximum duration of $5000 \mathrm{~ms}$. When serial order was assessed, a digit was presented in the same position for a maximum of $5000 \mathrm{~ms}$. The interstimulus interval was $400 \mathrm{~ms}$. The task involved 4 blocks of 24 trials each, each load level (i.e. size 4 or 7 ) being repeated twice, for a total of 48 trials per condition. The different load levels were presented in counterbalanced order (4-7-7-4), which was kept constant across participants. Relative accuracy was computed using correct location and correct order for load 4 and load 7 and used to index performance.

\subsubsection{General cognitive abilities}

The Digit Symbol Test, a subtest of the "Wechsler Adult Intelligence Scale Revised" (Wechsler, 1981), assesses perceptual speed (fluid intelligence). The Spota-Word Test is a test of verbal knowledge (crystallized intelligence; Lindenberger, Mayr, \& Kliegl, 1993). It is a forced-choice test that requires participants to spot real words in a list of pseudowords. 




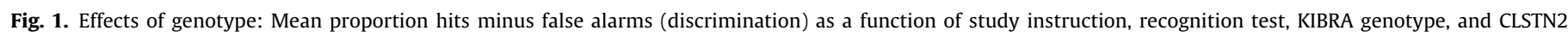
genotype. Error bars depict standard errors around the means.

\subsection{Statistical analysis}

For the Item-Pair-Memory Task, proportion of hits, proportion of false alarms, and discrimination (proportion of hits minus false alarms) were computed for each participant and condition. Participants with more than $20 \%$ non-responses in any of the conditions were excluded from further analysis (initial sample size $=394$ subjects; 11 subjects excluded). The relative proportion of excluded subjects did not differ across the four genotype groups (CLSTN2 T/T and KIBRA C/C $=0.04$, CLSTN2 T/T and KIBRA T-carrier $=0.02$; CLSTN2 C-carrier and KIBRA C/C $=0.02$, CLSTN2 C-carrier and KIBRA T-carrier $=0.04 ; \chi^{2}(3)=1.04, p>.10$ ). The memory data were analyzed using mixed-effect models with maximum-likelihood estimation ('Proc Mixed' procedure) using SAS 9.1 for Windows (SAS Institute Inc., Cary, NC, USA). Because the distribution of sex differed among the four genotype groups $\left(\chi^{2}(3)=10.05, p<.05\right)$ and women have an episodic memory advantage (Herlitz, Nilsson, \& Bäckman, 1997; Lewin, Wolgers, \& Herlitz, 2001), we included sex as an additional factor in the analyses. In contrast to standard analyses of variance (ANOVAs), mixed-effects models allow for differences in variances and covariances between groups. For the current data set, this is a more suitable approach because of the multivariate heterogeneity of variances and covariances in our data, as reflected in the Box's $M$ test, Box-M $=125.34, F(70,30622.54)=1.69, p<.0001$. All effects remained statistically significant when subjects with negative hits minus false alarm rates in at least one condition were excluded $(n=37)$.

To determine whether the two polymorphisms had an effect on demographic variables, we computed $\chi^{2}$-tests for sex and smoking habits (smoker, non-smoker) and 3-way ANOVAs with age or years of education as the dependent variable and KIBRA, CLSTN2 and sex as the independent variables using SPSS for Windows 15.0 (SPSS, Chicago, IL, USA).

Effects of the two polymorphisms in the WCST (perseverative errors and sum of correct responses), the Digit Symbol Test (number of completed items) and the Spot-a-Word Test (proportion correct) were also analyzed using 3-way factorial ANOVAs in SPSS with KIBRA, CLSTN2 and sex as between-subject factors. Because of the multivariate heterogeneity of variances and covariances for the SWM Task, as reflected in the Box's $M$ test, Box-M $=69.64, F(21,51948.17)=3.23, p<.0001$, we used a mixed-effect model with maximum-likelihood estimation ('Proc Mixed' procedure) using SAS 9.1 for this task. Accuracy in the SWM Task was examined in a 4-way model with KIBRA, CLSTN2 and sex as between-subject factors and load (4 items, 7 items) as within-subject factor.

\section{Results}

Proportion of hits minus false alarms for the 4 experimental conditions across genotype group is presented in Fig. 1. A study instruction (item, pair) $\times$ recognition test (item, associative $) \times$ KIBRA carrier status $(\mathrm{C} / \mathrm{C}$, T-carrier $) \times$ CLSTN2 carrier status (TT, C-carrier) $\times$ sex mixed model revealed a significant main effect for study instruction, $F(1,111)=111.46, p<.0001$, with higher performance when participants were instructed to study the word pairs. There was also a reliable main effect of recognition test, $F(1,111)=253.66, p<.0001$, with higher performance on the item test compared to the associative test. These findings replicate the original results of Naveh-Benjamin (2000). The interaction between study instruction and recognition test was also significant, $F(1,144)=180.00, p<.0001$, with the lowest performance when subjects were instructed to study items but pairs had to be recognized.

In addition, we found a significant main effect for sex, $F(1,83.4)=15.56, p<.001$, with higher performance for women than men (Fig. 2). The interactions between sex and study instruction, $F(1,111)=6.65, p<.05)$, and sex and recognition test, $F(1,111)=4.14$, $p<.05$, were also significant. These interactions reflected the facts that the female advantage was larger under pair instruction compared to item instruction, as well as in associative recognition relative to item recognition.

Of critical importance, we found a significant main effect for KIBRA genotype, $F(1,83.4)=4.16, p<.05$, with higher performance of $\mathrm{T}$-allele carriers confirming the initial results of Papassotiropoulos et al. (2006). There was no significant main effect for CLSTN2 carrier status, $F(1,83.4)=0.23, p>.10$. Consistent with our hypothesis, however, there was a significant KIBRA $\times$ CLSTN2 interaction, $F(1,83.4)=9.40, p<.005$. Follow-up $t$-tests revealed that subjects who carry the KIBRA T-allele and the CLSTN2 C-allele outperformed subjects of the other genotype groups (compared to CLSTN2 T/T and KIBRA C/C, $t(99.99)=-2.40, p<.05$; compared to CLSTN2 T/T and KIBRA T-carrier, $t(98.21)=-2.53, p<.05$; compared to CLSTN2 C-carrier and KIBRA T-carrier, $t(79.63)=-3.01, p<.005)$. No other genotype group comparisons were significant. The 2-way interaction of KIBRA and study instruction was marginally significant, $F(1,111)=3.59, p=.06$, with larger performance gains in the pair instruction condition compared to the item condition for $\mathrm{T}$ allele carriers than for $\mathrm{C} / \mathrm{C}$-carriers.

The results for hits and for false alarms are shown as Supplementary Information. The mixed models for these variables revealed similar effects as the analysis on discrimination.

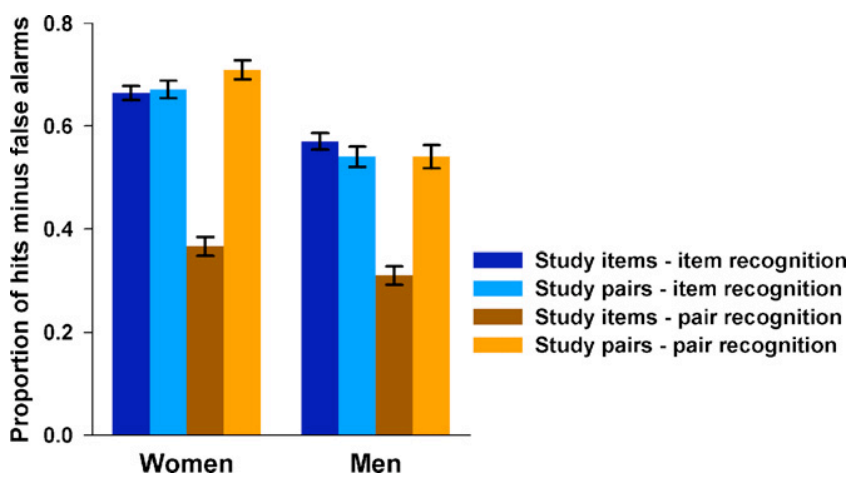

Fig. 2. Effects of gender: Mean proportion hits minus false alarms (discrimination) as a function of study instruction, recognition test, and gender. Error bars depict standard errors around the means. 
Genotype did not significantly affect the other cognitive measures (see Table 1). There were no main effects of KIBRA or CLSTN2 and no interaction effects for Digit Symbol, Spot-a-Word, WCST, or SWM $(p>.10)$. Sex was not equally distributed over the four genotype groups, $\chi^{2}(3)=10.05, p<.05$. The other demographic variables were not influenced by genotype (Table 1 ).

\section{Discussion}

We investigated whether gene-gene interactions influence episodic memory performance. Specifically, we tested the hypothesis that two SNPs located in the KIBRA and CLSTN2 genes exert an interactive effect on episodic memory. In addition, we examined whether the genotype effects would be modulated by the associative demands of the episodic memory task.

Carriers of the KIBRA rs17070145 T-allele showed higher episodic memory performance than carriers of the $C / C$ genotype. This result confirms the original finding by Papassotiropoulos et al. (2006) and data from several subsequent studies (Almeida et al., 2008; Bates et al., 2009; Corneveaux et al., in press; Schaper et al., 2008), although another recent investigation failed to find significant effects of the KIBRA polymorphism on episodic memory performance in two independent samples (Need et al., 2008).

Further, consistent with expectations, we found that the positive effect of the KIBRA T-allele was enhanced by the CLSTN2 rs6439886 C-allele: KIBRA T-allele carriers who also carried the CLSTN2 C-allele, which was previously reported to be beneficial to episodic memory (Jacobsen et al., 2009; Papassotiropoulos et al., 2006), outperformed subjects with the other genotype combinations. Subjects who also carried the CLSTN2 C-allele but were homozygous for the KIBRAC-allele performed as poorly as the other two genotype groups. This interaction explains why, in contrast to KIBRA, we did not find a main effect of the CLSTN2 polymorphism on episodic memory performance. Advantageous effects of the CLSTN2 C-allele on episodic memory have been reported in two studies (Jacobsen et al., 2009; Papassotiropoulos et al., 2006). However, Papassotiropoulos et al. (2006) did not replicate this effect in an additional sample. The present results suggest that the beneficial effects of the CLSTN2 C-alleles on episodic memory performance may have been masked by opposing effects of the different KIBRA alleles resulting in an epistatic interaction. Therefore, the effect of CLSTN2 polymorphism on episodic memory seems to be generally smaller than that of the KIBRA polymorphism. Support for this notion comes from neuroimaging studies. The different KIBRA genotypes affect hippocampal activity during episodic memory retrieval (Papassotiropoulos et al., 2006). In contrast, non-smoking adolescents show the beneficial effect of the CLSTN2 C-allele at the behavioral level but not with respect to activation of MTL structures (Jacobsen et al., 2009). Also, it is possible that the CLSTN2 effects are more susceptible to additional variables. Smoking in adolescence reverses the beneficial effect of the C-allele at a behavioral level and is additionally associated with increased activation of the parahippocampal gyrus indicative of reduced processing efficiency in the MTL during episodic memory (Jacobsen et al., 2009). However, smoking cannot account for the gene-gene interaction observed in our study, because smoking habits did not vary across genotype groups.

The present data suggest that the beneficial effects of the KIBRA T-allele are enhanced by the presence of the CLSTN2 C-allele, whereas the performance-enhancing effects of the CLSTN2 C-allele depend on KIBRA genotype. The size and the magnitude of the effect of the KIBRA and CLSTN2 polymorphisms on episodic memory performance may, therefore, depend on the varying distributions of the combined genotypes in different studies. Further studies investigating the interaction of KIBRA and CLSTN2 at a molecular level have to elucidate the nature of this interaction. Together, these results suggest that individual differences in the KIBRA and CLSTN2 genotypes interactively mediate episodic memory performance. Importantly, these genetic effects were confined to episodic memory; no reliable effects were found for measures of fluid and crystallized intelligence, executive functioning, or spatial working memory. This pattern indicates that both genes exert their effects in localized brain regions likely including the MTL.

In addition to the interaction between KIBRA and CLSTN2, we asked whether the magnitude of genetic effects on episodic memory is modulated by the associative requirements of the task. Here, we observed a marginally significant interaction between KIBRA genotype and study instruction $(p=.06)$, with carriers of the KIBRA T-allele showing larger performance benefits under the pairinstruction compared to the item-instruction condition than non-T carriers. This finding suggests that the benefit of the KIBRA T-allele increases with increasing associative demands of the memory task, that is, when subjects have to encode word pairs compared to single items. The ability to form and maintain memories has been linked to MTL functioning, particularly the hippocampus and surrounding cortices (Davachi, 2006; Eichenbaum et al., 2007; Rempel-Clower, Zola, Squire, \& Amaral, 1996; Scoville \& Milner, 1957; Squire et al., 2007, Zola-Morgan et al., 1986). In addition, hippocampal activity increases with increasing associative demands of an episodic memory task and is linked to performance in associative memory tests (Achim et al., 2007; Addis \& McAndrews, 2006; Davachi et al., 2003; Davachi \& Wagner, 2002; Giovanello et al., 2004; Mitchell, Johnson, Raye, \& D'Esposito, 2000; Ranganath, Cohen, Dam, \& D’Esposito, 2004; Staresina \& Davachi, 2008; Yonelinas et al., 2001). These results again point to the hippocampus as a possible target location for the modulating effects of the KIBRA polymorphism on episodic memory. This interpretation is supported by evidence suggesting that KIBRA T-allele carriers show lower hippocampal activity than non-T carriers during retrieval of associative information (Papassotiropoulos et al., 2006). These results have been interpreted to reflect increased processing requirements in the hippocampus among non-T-allele carriers, because of either deficient encoding of associations or inefficient retrieval processes (Papassotiropoulos et al., 2006). A recent study found effects of the KIBRA genotype for the list-learning paradigm used by Papassotiropoulos and colleagues but not for a story recall task (Bates et al., 2009). The authors interpreted these results by a genotype effect on item-based processing but no effect on relational processing. This interpretation, however, was based on effects in two different samples with different sample sizes ( $n=2091$ vs. $n=542$ ) and mean ages (67 vs. 79 years). In addition, the tasks used varied not only in their associative demands, but also required different processing strategies. Whereas item memory seems to depend on MTL structures (Eichenbaum et al., 2007; Squire, Stark, \& Clark, 2004), story processing requires the strategic manipulation and organization of information, which largely depends on the prefrontal cortex (Addis \& McAndrews, 2006; Bor, Cumming, Scott, \& Owen, 2004; Fletcher, Shallice, \& Dolan, 2000). Therefore, the results may reflect differences in task strategy as opposed to differences in associative task demands.

Regarding potential effects of the KIBRA and CLSTN2 genotypes on other task factors, it has been suggested that recognition memory depends on two different processes: Conscious recollection of an item and its associated contextual information, and a sense of familiarity of the specific features of a stimulus (Mandler, 1980; Yonelinas \& Levy, 2002). According to several theorists, these two processes are supported by different brain regions (Davachi, 2006; Eichenbaum et al., 2007; Mayes, Montaldi, \& Migo, 2007). In addition, findings indicate that reductions in hit rates reflect recollection deficits, whereas increases in false alarm rates reflect a 
greater reliance on familiarity-based recognition (Castel \& Craik, 2003; Farovik, Dupont, Arce, \& Eichenbaum, 2008; Fortin, Wright, \& Eichenbaum, 2004; Jones \& Jacoby, 2001; Searcy, Bartlett, \& Memon, 1999). Separate analyses of hit and false alarm rates in our data confirmed the pattern of results for discrimination, indicating that the genotype combinations affected both variables similarly: Subjects homozygous for the KIBRA C-allele who also possess the CLSTN2 C-allele exhibited reduced hit rates, suggesting poorer recollection of previously experienced stimuli and, at the same time, increased false alarm rates suggesting a greater reliance on familiarity-based recognition. If increased false alarm rates indicate a greater reliance on familiarity (e.g., Castel \& Craik, 2003), then it could be argued that persons with the unfavorable genotype combination are impaired in conscious recollection leaving familiarity relatively intact.

Although the present findings are biologically plausible, it should be noted that both the KIBRA and CLSTN2 SNPs are located in introns. Thus, it is highly likely that neither of them directly conferred the behavioral effects observed in this study. Rather, the associated intronic SNPs may be in linkage disequilibrium with nearby sequence variations that remain to be identified in future research.

Further, the present findings confirm the female superiority in verbal episodic memory (Herlitz et al., 1997; Lewin et al., 2001). In addition, the results indicate that this female advantage is modulated by the associative demands of the memory task: Women performed better under pair instructions than under item instructions, and the performance advantage for women over men was greater for pair than for item recognition. In addition to a general performance advantage in verbal episodic memory, these results suggest that the advantage for women increases with increasing associative demands, either when encoding requires building associations between items or when recognition involves recollection of relations between more than one item. The greater effect size for sex regarding study instructions suggests that the source of this sex difference is more linked to encoding than to retrieval processes. However, no interactions including sex and genotype were significant, indicating that sex differences in episodic memory are independent of the molecular functions of KIBRA or CLSTN2.

In conclusion, we show that the KIBRA and CLSTN2 genes interactively modulate episodic memory performance. Furthermore, the effect of the KIBRA polymorphism is modulated by the associative requirements of the task. Additional genes have been implicated in episodic memory functioning, including BDNF (Egan et al., 2003; Goldberg et al., 2008; Hariri et al., 2003; Ho et al., 2006; Miyajima et al., 2008), APOE (Deary et al., 2002; Mondadori et al., 2007; Small, Rosnick, Fratiglioni, \& Backman, 2004), and 5HT2A (de Quervain et al., 2003; Reynolds, Jansson, Gatz, \& Pedersen, 2006; Sigmund, Vogler, Huynh, de Quervain, \& Papassotiropoulos, 2008; Wagner, Schuhmacher, Schwab, Zobel, \& Maier, 2008). Although genetic interactions for a specific cognitive function are complex and computationally demanding, it has been suggested that, for reasons of evolutionary efficiency, the number of epistatic relationships should remain relatively small (Bonner, 1988; Kauffman, 1993; McClearn, 2006). Therefore, it might be possible to identify a limited group of target genes that are critical to episodic memory performance. Future studies with large samples using different experimental paradigms have to elucidate how these different genes contribute to different aspects of episodic memory and the high heritability for this form of memory.

\section{Acknowledgements}

This research was supported by the Max Planck Society, including a grant from the innovation fund of the Max Planck Society
(M.FE.A.BILD0002). L.B. was supported by grants from the Swedish Research Council (521-2007-2892) and Swedish Brain Power, and by an Alexander von Humboldt Research Award. We thank Kirsten Becker, Silke Becker, Alina Lukas, Ute Martin and Ludmila Müller for their help in project organization and Goran Papenberg for his assistance with data analysis as well as the student research assistants. The authors declare that there is no actual or potential conflict of interest in relation to this manuscript.

\section{Appendix A. Supplementary data}

Supplementary data associated with this article can be found, in the online version, at doi:10.1016/j.neuropsychologia.2009.09.031.

\section{References}

Achim, A. M., Bertrand, M. C., Montoya, A., Malla, A. K., \& Lepage, M. (2007). Medial temporal lobe activations during associative memory encoding for arbitrary and semantically related object pairs. Brain Research, 1161, 46-55.

Addis, D. R., \& McAndrews, M. P. (2006). Prefrontal and hippocampal contributions to the generation and binding of semantic associations during successful encoding. Neuroimage, 33, 1194-1206.

Alarcon, M., Plomin, R., Fulker, D. W., Corley, R., \& DeFries, J. C. (1998). Multivariate path analysis of specific cognitive abilities data at 12 years of age in the Colorado Adoption Project. Behavior Genetics, 28, 255-264.

Almeida, O. P., Schwab, S. G., Lautenschlager, N. T., Morar, B., Greenop, K. R., Flicker, L., et al. (2008). KIBRA genetic polymorphism influences episodic memory in later life, but does not increase the risk of mild cognitive impairment. Journal of Cellular and Molecular Medicine, 12, 1672-1676.

Bates, T. C, Price, J. F., Harris, S. E., Marioni, R. E., Fowkes, F. G., Stewart, M. C., et al. (2009). Association of KIBRA and memory. Neuroscience Letters, 458, 140-143.

Bonner, J. T. (1988). The Evolution of Complexity by Means of Natural Selection. Princeton University Press.

Bor, D., Cumming, N., Scott, C. E., \& Owen, A. M. (2004). Prefrontal cortical involvement in verbal encoding strategies. European Journal of Neuroscience, 19, 3365-3370.

Bouchard, T. J., Jr., \& McGue, M. (2003). Genetic and environmental influences on human psychological differences. Journal of Neurobiology, 54, 4-45.

Buther, K., Plaas, C., Barnekow, A., \& Kremerskothen, J. (2004). KIBRA is a novel substrate for protein kinase Czeta. Biochemical and Biophysical Research Communications, 317, 703-707.

Castel, A. D., \& Craik, F. I. (2003). The effects of aging and divided attention on memory for item and associative information. Psychology and Aging, 18, 873-885.

Corneveaux, J. J., Liang, W. S., Reiman, E. M., Webster, J. A., Myers, A. J., Zismann, V. L., et al. (in press). Evidence for an association between KIBRA and late-onset Alzheimer's disease. Neurobiology of Aging.

Davachi, L. (2006). Item, context and relational episodic encoding in humans. Current Opinion in Neurobiology, 16, 693-700.

Davachi, L., Mitchell, J. P. \& Wagner, A. D. (2003). Multiple routes to memory: Distinct medial temporal lobe processes build item and source memories. Proceedings of the National Academy of Sciences of the United States of America, 100, 2157-2162.

Davachi, L., \& Wagner, A. D. (2002). Hippocampal contributions to episodic encoding: Insights from relational and item-based learning. Journal of Neurophysiology, 88 982-990.

de Quervain, D. J., Henke, K., Aerni, A., Coluccia, D., Wollmer, M. A., Hock, C., et al. (2003). A functional genetic variation of the 5-HT2a receptor affects human memory. Nature Neuroscience, 6, 1141-1142.

Deary, I. J., Whiteman, M. C., Pattie, A., Starr, J. M., Hayward, C., Wright, A. F., et al. (2002). Cognitive change and the APOE epsilon 4 allele. Nature, 418, 932.

Dudai, Y. (2002). Molecular bases of long-term memories: A question of persistence. Current Opinion in Neurobiology, 12, 211-216.

Egan, M. F., Kojima, M., Callicott, J. H., Goldberg, T. E., Kolachana, B. S., Bertolino, A., et al. (2003). The BDNF val66met polymorphism affects activity-dependent secretion of BDNF and human memory and hippocampal function. Cell, 112, 257-269.

Eichenbaum, H., Yonelinas, A. P., \& Ranganath, C. (2007). The medial temporal lobe and recognition memory. Annual Review of Neuroscience, 30, 123-152.

Farovik, A., Dupont, L. M., Arce, M., \& Eichenbaum, H. (2008). Medial prefrontal cortex supports recollection, but not familiarity, in the rat. Journal of Neuroscience, 28 , 13428-13434.

Finkel, D, Pedersen, N. L., Plomin, R., \& McClearn, G. E. (1998). Longitudinal and cross-sectional twin data on cognitive abilities in adulthood: The Swedish Adoption/Twin Study of Aging. Developmental Psychology, 34, 1400-1413.

Fletcher, P. C., Shallice, T., \& Dolan, R. J. (2000). Sculpting the response space-An account of left prefrontal activation at encoding. Neuroimage, 12, 404-417.

Fortin, N. J., Wright, S. P., \& Eichenbaum, H. (2004). Recollection-like memory retrieval in rats is dependent on the hippocampus. Nature, 431, 188-191.

Giovanello, K. S., Schnyer, D. M., \& Verfaellie, M. (2004). A critical role for the anterior hippocampus in relational memory: Evidence from an fMRI study comparing associative and item recognition. Hippocampus, 14, 5-8. 
Goldberg, T. E., Iudicello, J., Russo, C., Elvevag, B., Straub, R., Egan, M. F., et al. (2008). BDNF Val66Met polymorphism significantly affects d' in verbal recognition memory at short and long delays. Biological Psychology, 77, 20-24.

Hariri, A. R., Goldberg, T. E., Mattay, V. S., Kolachana, B. S., Callicott, J. H., Egan, M. F., et al. (2003). Brain-derived neurotrophic factor val66met polymorphism affects human memory-related hippocampal activity and predicts memory performance. Journal of Neuroscience, 23, 6690-6694.

Heaton, D., Chelune, G. J., Talley, J. L., Kay, G. G., \& Curtis, G. (1993). Wisconsin card sorting test manual: Revised and expanded. Odessa: Psychological Assessment Resources.

Henke, K., Weber, B., Kneifel, S., Wieser, H. G., \& Buck, A. (1999). Human hippocampus associates information in memory. Proceedings of the National Academy of Sciences of the United States of America, 96, 5884-5889.

Herlitz, A., Nilsson, L. G., \& Bäckman, L. (1997). Gender differences in episodic memory. Memory and Cognition, 25, 801-811.

Hintsch, G., Zurlinden, A., Meskenaite, V., Steuble, M., Fink-Widmer, K., Kinter, J., et al. (2002). The calsyntenins-a family of postsynaptic membrane proteins with distinct neuronal expression patterns. Molecular and Cellular Neurosciences, 21, 393-409.

Ho, B. C., Milev, P., O’Leary, D. S., Librant, A., Andreasen, N. C., \& Wassink, T. H. (2006). Cognitive and magnetic resonance imaging brain morphometric correlates of brain-derived neurotrophic factor Val66Met gene polymorphism in patients with schizophrenia and healthy volunteers. Archives of General Psychiatry, 63, 731-740.

Hoerndli, F. J., Walser, M., Frohli, H. E., de, Q. D., Papassotiropoulos, A., \& Hajnal, A. (2009). A conserved function of $C$. elegans CASY-1 calsyntenin in associative learning. PLOS ONE, 4, e4880.

Ikeda, D. D., Duan, Y., Matsuki, M., Kunitomo, H., Hutter, H., Hedgecock, E. M., et al. (2008). CASY-1, an ortholog of calsyntenins/alcadeins, is essential for learning in Caenorhabditis elegans. Proceedings of the National Academy of Sciences of the United States of America, 105, 5260-5265.

Jacobsen, L. K., Picciotto, M. R., Heath, C. J., Mencl, W. E., \& Gelernter, J. (2009). Allelic variation of calsyntenin 2 (CLSTN2) modulates the impact of developmental tobacco smoke exposure on mnemonic processing in adolescents. Biological Psychiatry, 65, 671-679.

Johannsen, S., Duning, K., Pavenstadt, H., Kremerskothen, J., \& Boeckers, T. M. (2008). Temporal-spatial expression and novel biochemical properties of the memoryrelated protein KIBRA. Neuroscience, 155, 1165-1173.

Jones, T. C., \& Jacoby, L. L. (2001). Feature and conjunction errors in recognition memory: Evidence for dual-processing theory. Journal of Memory and Language, 45, 82-102.

Kandel, E. R. (2001). The molecular biology of memory storage: A dialogue between genes and synapses. Science, 294, 1030-1038.

Kauffman, S. A. (1993). The origins of order: Self-organization and selection in evolution. Oxford University Press.

Klingberg, T., O'Sullivan, B. T., \& Roland, P. E. (1997). Bilateral activation of frontoparietal networks by incrementing demand in a working memory task. Cerebral Cortex, 7, 465-471.

Koppel, J., \& Goldberg, T. (2009). The genetics of episodic memory. Cognitive Neuropsychiatry, 14(4), 356-376.

Kremerskothen, J., Plaas, C., Buther, K., Finger, I., Veltel, S., Matanis, T., et al. (2003). Characterization of KIBRA, a novel WW domain-containing protein. Biochemical and biophysical research communications, 300, 862-867.

Lewin, C., Wolgers, G., \& Herlitz, A. (2001). Sex differences favoring women in verbal but not in visuospatial episodic memory. Neuropsychology, 15, 165-173.

Lindenberger, U., Mayr, U., \& Kliegl, R. (1993). Speed and intelligence in old age. Psychology and Aging, 8, 207-220.

Lindenberger, U., Nagel, I. E., Chicherio, C., Li, S. C., Heekeren, H. R., \& Backman, L. (2008). Age-related decline in brain resources modulates genetic effects on cognitive functioning. Frontiers in Neuroscience, 2, 234-244.

Mandler, G. (1980). Recognizing: The judgment of previous occurrence. Psychological Review, 87, 252-271.

Mayes, A., Montaldi, D., \& Migo, E. (2007). Associative memory and the medial temporal lobes. Trends in Cognitive Sciences, 11, 126-135.

McClearn, G. E. (2006). Contextual genetics. Trends in Genetics, 22, 314-319.

McClearn, G. E., Johansson, B., Berg, S., Pedersen, N. L., Ahern, F., Petrill, S. A., et al. (1997). Substantial genetic influence on cognitive abilities in twins 80 or more years old. Science, 276, 1560-1563.

Mitchell, K. J., Johnson, M. K., Raye, C. L., \& D’Esposito, M. (2000). fMRI evidence of age-related hippocampal dysfunction in feature binding in working memory. Brain Research Cognitive Brain Research, 10, 197-206.

Miyajima, F., Ollier, W., Mayes, A., Jackson, A., Thacker, N., Rabbitt, P., et al. (2008). Brain-derived neurotrophic factor polymorphism Val66Met influences cognitive abilities in the elderly. Genes, Brain, and Behavior, 7, 411-417.

Mondadori, C. R., de Quervain, D. J., Buchmann, A., Mustovic, H., Wollmer, M. A., Schmidt, C. F., et al. (2007). Better memory and neural efficiency in young apolipoprotein E epsilon4 carriers. Cerebral Cortex, 17, 1934-1947.

Nacmias, B., Bessi, V., Bagnoli, S., Tedde, A., Cellini, E., Piccini, C., et al. (2008). KIBRA gene variants are associated with episodic memory performance in subjective memory complaints. Neuroscience Letters, 436, 145-147.

Nagel, I. E., Chicherio, C., Li, S. C., von, O. T., Sander, T., Villringer, A., et al. (2008). Human aging magnifies genetic effects on executive functioning and working memory. Frontiers in Human Neuroscience, $2,1$.
Naveh-Benjamin, M. (2000). Adult age differences in memory performance: Tests of an associative deficit hypothesis. Journal of Experimental Psychology: Learning, Memory and Cognition, 26, 1170-1187.

Need, A. C., Attix, D. K., McEvoy, J. M., Cirulli, E. T., Linney, K. N., Wagoner, A. P., et al. (2008). Failure to replicate effect of Kibra on human memory in two large cohorts of European origin. American Journal of Medical Genetics. Part B, Neuropsychiatric Genetics, 147B, 667-668.

Papassotiropoulos, A., Stephan, D. A., Huentelman, M. J., Hoerndli, F. J., Craig, D. W. Pearson, J. V., et al. (2006). Common Kibra alleles are associated with human memory performance. Science, 314, 475-478.

Ranganath, C., Cohen, M. X., Dam, C., \& D’Esposito, M. (2004). Inferior temporal, prefrontal, and hippocampal contributions to visual working memory maintenance and associative memory retrieval. Journal of Neuroscience, 24, 3917-3925.

Rempel-Clower, N. L, Zola, S. M., Squire, L. R., \& Amaral, D. G. (1996). Three cases of enduring memory impairment after bilateral damage limited to the hippocampal formation. Journal of Neuroscience, 16(16), 5233-5255.

Reynolds, C. A., Jansson, M., Gatz, M., \& Pedersen, N. L. (2006). Longitudinal change in memory performance associated with HTR2A polymorphism. Neurobiology of Aging, 27, 150-154.

Rodriguez-Rodriguez, E., Infante, J., Llorca, J., Mateo, I., Sanchez-Quintana, C., GarciaGorostiaga, I., et al. (2009). Age-dependent association of KIBRA genetic variation and Alzheimer's disease risk. Neurobiology of Aging, 30, 322-324.

Schaper, K., Kolsch, H., Popp, J., Wagner, M., \& Jessen, F. (2008). KIBRA gene variants are associated with episodic memory in healthy elderly. Neurobiology of Aging, $29,1123-1125$.

Scoville, W. B., \& Milner, B. (1957). Loss of recent memory after bilateral hippocampal lesions. Journal of Neurology, Neurosurgery, and Psychiatry, 20(1), 11-21.

Searcy, J. H., Bartlett, J. C., \& Memon, A. (1999). Age differences in accuracy and choosing in eyewitness identification and face recognition. Memory and Cognition, 27, $538-552$

Shobe, J. (2002). The role of PKA, CaMKII, and PKC in avoidance conditioning: Permissive or instructive? Neurobiology of Learning and Memory, 77, 291-312.

Sigmund, J. C., Vogler, C., Huynh, K. D., de Quervain, D. J., \& Papassotiropoulos, A. (2008). Fine-mapping at the HTR2A locus reveals multiple episodic memoryrelated variants. Biological Psychology, 79, 239-242.

Small, B. J., Rosnick, C. B., Fratiglioni, L., \& Backman, L. (2004). Apolipoprotein E and cognitive performance: A meta-analysis. Psychology and Aging, 19, 592-600.

Squire, L. R., \& Kandel, E. R. (1999). Memory: From mind to molecules. New York Scientific American Books.

Squire, L. R., Stark, C. E., \& Clark, R. E. (2004). The medial temporal lobe. Annual Review of Neuroscience, 27, 279-306.

Squire, L. R., Wixted, J. T., \& Clark, R. E. (2007). Recognition memory and the medial temporal lobe: A new perspective. Nature Reviews Neuroscience, 8, 872-883.

Staresina, B. P., \& Davachi, L. (2008). Selective and shared contributions of the hippocampus and perirhinal cortex to episodic item and associative encoding Journal of Cognitive Neuroscience, 20, 1478-1489.

Stelzel, C., Basten, U., Montag, C., Reuter, M., \& Fiebach, C. J. (2009). Effects of dopamine-related gene-gene interactions on working memory component processes. European Journal of Neuroscience, 29, 1056-1063.

Tan, H. Y., Chen, Q., Sust, S., Buckholtz, J. W., Meyers, J. D., Egan, M. F., et al. (2007) Epistasis between catechol-O-methyltransferase and type II metabotropic glutamate receptor 3 genes on working memory brain function. Proceedings of the National Academy of Sciences of the United States of America, 104, 12536-12541.

Thapar, A., Petrill, S. A., \& Thompson, L. A. (1994). The heritability of memory in the Western Reserve Twin Project. Behavior Genetics, 24, 155-160.

Tonegawa, S., Nakazawa, K., \& Wilson, M. A. (2003). Genetic neuroscience of mammalian learning and memory. Philosophical Transactions of the Royal Society of London, Series B: Biological Sciences, 358, 787-795.

Tulving, E. (2002). Episodic memory: From mind to brain. Annual Review of Psychology, 53, 1-25.

Tulving, E. (1972). Episodic and semantic memory. In E. Tulving, \& W. Donaldson (Eds.), Organization of memory. New York: Academic Press.

Waddell, S., \& Quinn, W. G. (2001). What can we teach Drosophila? What can they teach us? Trends in Genetics, 17, 719-726.

Wagner, M., Schuhmacher, A., Schwab, S., Zobel, A., \& Maier, W. (2008). The His452Tyr variant of the gene encoding the 5-HT2A receptor is specifically associated with consolidation of episodic memory in humans. International Journal of Neuropsychopharmacology, 11, 1163-1167.

Wechsler, D. (1981). Wechsler Adult Intelligence Scale-Revised: Manual. New York: Psychological Cooperation.

Yacubian, J., Sommer, T., Schroeder, K., Glascher, J., Kalisch, R., Leuenberger, B., et al. (2007). Gene-gene interaction associated with neural reward sensitivity. Proceedings of the National Academy of Sciences of the United States of America, 104, 8125-8130.

Yonelinas, A. P., Hopfinger, J. B., Buonocore, M. H., Kroll, N. E., \& Baynes, K. (2001). Hippocampal, parahippocampal and occipital-temporal contributions to associative and item recognition memory: An fMRI study. Neuroreport, 12, 359-363.

Yonelinas, A. P., \& Levy, B. J. (2002). Dissociating familiarity from recollection in human recognition memory: Different rates of forgetting over short retention intervals. Psychonomic Bulletin \& Review, 9, 575-582.

Zola-Morgan, S., Squire, L. R., \& Amaral, D. G. (1986). Human amnesia and the medial temporal region: Enduring memory impairment following a bilateral lesion limited to field CA1 of the hippocampus. Journal of Neuroscience, 6(10), 2950-2967. 